\title{
A Time and Motion Study of Pharmacists and Pharmacy Technicians Obtaining Admission Medication Histories
}

\author{
Caroline B. Nguyen, PharmD, BCPS ${ }^{1 *}$, Rita Shane, PharmD, FASHP, FCSHP ${ }^{1}$, Douglas S. Bell, MD, PhD ${ }^{2,3}$, \\ Galen Cook-Wiens, $\mathrm{MS}^{4}$, Joshua M. Pevnick, MD, MSHS ${ }^{5}$
}

\begin{abstract}
${ }^{1}$ Department of Pharmacy Services, Cedars-Sinai Health System, Los Angeles, California; ${ }^{2}$ RAND Health, Santa Monica, California; ${ }^{3}$ Department of Medicine, Division of General Internal Medicine and Health Services Research, David Geffen School of Medicine at UCLA, Los Angeles, California; ${ }^{4}$ Biostatistics, Bioinformatics and Research Informatics Center, Samuel Oschin Comprehensive Cancer Institute, Cedars-Sinai Health System, Los Angeles, California; ${ }^{5}$ Department of Medicine, Division of General Internal Medicine, Cedars-Sinai Health System, Los Angeles, California.
\end{abstract}

Pharmacists' admission medication histories (AMHs) are known to reduce adverse drug events (ADEs). Pharmacistsupervised pharmacy technicians (PSPTs) have also been used in this role. Nonetheless, few studies estimate the costs of utilizing PSPTs to obtain AMHs. We used time and motion methodology to study the time and cost required for pharmacists and PSPTs to obtain AMHs for patients at high risk for ADEs. Pharmacists and PSPTs required 58.5 (95\% confidence interval $[\mathrm{Cl}], 46.9-70.1)$ and $79.4(95 \% \mathrm{Cl}, 59.1-99.8)$ minutes per patient, respectively $(P=0.14)$. PSPT-obtained
AMHs also required $26.0(95 \% \mathrm{Cl}, 14.9-37.1)$ minutes of pharmacist supervision per patient. Based on 2015 US Bureau of Labor Statistics wage data, we estimated the cost of having pharmacists and PSPTs obtain AMHs to be $\$ 55.91$ (95\% Cl, 44.9-67.0) and $\$ 45.00$ (95\% Cl, 29.7-60.4), respectively, which included pharmacist supervisory cost, per patient $(P=0.32)$. Thus, we found no statistically significant difference in time or cost between the two provider types. Journal of Hospital Medicine 2017;12:180-183. (C) 2017 Society of Hospital Medicine
Using pharmacists to obtain admission medication histories (AMHs) reduces medication errors by $70 \%$ to $83 \%$ and resultant adverse drug events (ADEs) by $15 \% .^{1-3}$ Dissemination of this practice has been limited by several factors, including clinician practice models, staff availability, confusion in provider roles and accountability, and absence of standardized best practices. ${ }^{4-5}$ This paper assesses one of these barriers: the high cost of utilizing pharmacists. Third-person observer time and motion analysis shows that pharmacists require 46 and 92 minutes to obtain AMHs from medical and geriatric patients, ${ }^{6}$ respectively, resulting in pharmacist costs of $\$ 44$ to $\$ 88$ per patient, based on 2015 US Bureau of Labor Statistics (BLS) hourly wage data for pharmacists (\$57.34).

Pharmacist-supervised pharmacy technicians (PSPTs) achieve AMH accuracy comparable to pharmacists, ${ }^{8-9}$ but their hourly wages are only $26 \%$ of pharmacists'. ${ }^{7}$ We conducted a third-person observer time and motion study ${ }^{10}$ to compare the amount of time and labor cost necessary for pharmacists and PSPTs to obtain AMHs for patients at high risk for ADEs.

\section{METHODS}

This study originated as part of a randomized, controlled trial conducted during January-February 2014 at Cedars-Sinai

\footnotetext{
*Address for correspondence and reprint requests: Caroline B. Nguyen, PharmD, BCPS, 9014 Bolsa Ave., Westminster, CA 92683; Telephone: 714 376-6055; Fax: 714-890-7191; E-mail: cbnnguyen@gmail.com
}

Additional Supporting Information may be found in the online version of this article. Received: April 19, 2016; Revised: September 22, 2016; Accepted: October 16, 2016

2017 Society of Hospital Medicine 10.12788/jhm.2702
Medical Center (CSMC), an 896-bed, university-affiliated, not-for-profit hospital. ${ }^{9}$ Pharmacy staff included pharmacists, PGY-1 pharmacy residents, and pharmacy technicians, each of whom received standardized didactic and experiential training (Appendix 1).

The pharmacists' AMH and general pharmacy experience ranged from $<1$ to 3 years and $<1$ to 5 years, respectively. For PSPTs, AMH and general pharmacy experience ranged from $<1$ to 2 years and 1 to 17 years, respectively. Three additional pharmacists were involved in supervising PSPTs, and their experience fell within the aforementioned ranges, except for one pharmacist with general pharmacy experience of 16 years. The CSMC Institutional Review Board approved this study with oral consent from pharmacy staff.

For the trial, pharmacists and PSPTs obtained AMHs from 185 patients identified as high-risk for ADEs in the CSMC Emergency Department (ED). Patients were randomized into each arm using RANDI2 software ${ }^{11}$ if they met one of the trial inclusion criteria, accessed via electronic health record (EHR) (Appendix 2). For several days during this trial, a trained research nurse shadowed pharmacists and PSPTs to record tasks performed, as well as the actual time, including start and end times, dedicated to each task.

After excluding AMHs with incomplete data, we calculated mean AMH times and component task times (Table). We compared mean times for pharmacists and PSPTs using two sample $t$ tests (Table). We calculated mean times of tasks across only $\mathrm{AMHs}$ that required the task, mean times of tasks across all AMHs studied, regardless of whether the $\mathrm{AMH}$ required the task or not (assigning 0 minutes for the task if it was not required), and percent mean time of task per patient for providers combined (Table). 
TABLE. Observed Admission Medication History Tasks and Time Spent ${ }^{a}$

\begin{tabular}{|c|c|c|c|c|c|c|c|c|c|c|}
\hline \multirow[b]{2}{*}{$\begin{array}{l}\text { Observed } \\
\text { AMH Tasks }\end{array}$} & \multirow[b]{2}{*}{$\begin{array}{l}\text { Observed AMH } \\
\text { Task Descriptions }\end{array}$} & \multicolumn{4}{|c|}{$\begin{array}{l}\text { Mean Times Based on AMHs that Required this Task } \\
(\mathrm{n}=\text { reported in each section) }\end{array}$} & \multicolumn{5}{|c|}{$\begin{array}{c}\text { Mean Times Based Across All AMHs } \\
\text { (Combined } n=30, \text { Pharmacists } n=12, \text { PSPTs } n=18 \text { ) }\end{array}$} \\
\hline & & $\begin{array}{l}\text { Mean Time } \\
\text { for Providers } \\
\text { Combined } \\
\text { (minutes) }\end{array}$ & $\begin{array}{l}\text { Mean Time for } \\
\text { Pharmacists } \\
\text { (minutes) }\end{array}$ & $\begin{array}{l}\text { Mean Time } \\
\text { for PSPTs } \\
\text { (minutes) }\end{array}$ & $\begin{array}{c}P \\
\text { value }^{b}\end{array}$ & $\begin{array}{l}\text { Mean Time } \\
\text { for Providers } \\
\text { Combined } \\
\text { (minutes) }\end{array}$ & $\begin{array}{l}\text { Mean Time for } \\
\text { Pharmacists } \\
\text { (minutes) }\end{array}$ & $\begin{array}{l}\text { Mean Time } \\
\text { for PSPTs } \\
\text { (minutes) }\end{array}$ & $\begin{array}{c}P \\
\text { value }^{b}\end{array}$ & $\begin{array}{c}\text { \% Mean Time } \\
\text { per Patient for } \\
\text { Providers } \\
\text { Combined }\end{array}$ \\
\hline \multirow[t]{2}{*}{$\begin{array}{l}\text { Direct Patient } \\
\text { Care Activities }\end{array}$} & $\begin{array}{l}\text { Discussion with patient } \\
\text { and/or family member/ } \\
\text { caregiver at bedside }\end{array}$ & $\begin{array}{c}20.4 \\
(95 \% \mathrm{Cl} \\
15.5-25.2)\end{array}$ & $\begin{array}{c}19.1 \\
(95 \% \mathrm{Cl} \\
13.3-24.9)\end{array}$ & $\begin{array}{c}21.3 \\
(95 \% \mathrm{Cl} \\
13.9-28.8)\end{array}$ & .67 & $\begin{array}{c}14.3 \\
(95 \% \mathrm{Cl} \\
9.5-19.0)\end{array}$ & $\begin{array}{c}14.3 \\
(95 \% \mathrm{Cl} \\
7.8-20.9)\end{array}$ & $\begin{array}{c}14.2 \\
(95 \% \mathrm{Cl} \\
7.4-21.1)\end{array}$ & .98 & $\begin{array}{c}17.7 \% \\
(95 \% \mathrm{Cl} \\
12.0-23.4)\end{array}$ \\
\hline & & $\mathrm{n}=21$ & $\mathrm{n}=9$ & $\mathrm{n}=12$ & & & & & & \\
\hline \multirow[t]{10}{*}{$\begin{array}{l}\text { Utilizing } \\
\text { Secondary } \\
\text { Resources }\end{array}$} & $\begin{array}{l}\text { Obtain medication } \\
\text { information from } \\
\text { outpatient pharmacies } \\
\text { via phone and/or fax }\end{array}$ & $\begin{array}{c}15.8 \\
(95 \% \mathrm{Cl} \\
10.2-21.4)\end{array}$ & $\begin{array}{c}13.8 \\
(95 \% \mathrm{Cl} \\
8.9-18.6)\end{array}$ & $\begin{array}{c}17.4 \\
(95 \% \mathrm{Cl} \\
8.0-26.9)\end{array}$ & .54 & $\begin{array}{c}9.5 \\
(95 \% \mathrm{Cl} \\
5.1-13.8)\end{array}$ & $\begin{array}{c}9.2 \\
(95 \% \mathrm{Cl} \\
4.2-14.1)\end{array}$ & $\begin{array}{c}9.7 \\
(95 \% \mathrm{Cl} \\
3.1-16.2)\end{array}$ & .91 & $\begin{array}{c}11.6 \% \\
(95 \% \mathrm{Cl} \\
6.6-16.6)\end{array}$ \\
\hline & & $n=18$ & $\mathrm{n}=8$ & $n=10$ & & & & & & \\
\hline & $\begin{array}{l}\text { Obtain medication } \\
\text { information from care- } \\
\text { givers or family members } \\
\text { who are not present }\end{array}$ & $\begin{array}{c}8.8 \\
(95 \% \mathrm{Cl} \\
4.6-13.0)\end{array}$ & 17 & $\begin{array}{c}6.8 \\
(95 \% \mathrm{Cl} 5.1-8.6)\end{array}$ & $\mathrm{N} / \mathrm{A}^{\prime}$ & $\begin{array}{c}1.5 \\
(95 \% \mathrm{Cl} \\
0.1-2.8)\end{array}$ & $\begin{array}{c}1.4 \\
(95 \% \mathrm{Cl} \\
-1.4-4.2)\end{array}$ & $\begin{array}{c}1.5 \\
(95 \% \mathrm{Cl} \\
0.1-2.9)\end{array}$ & .74 & $\begin{array}{c}1.7 \% \\
(95 \% \mathrm{Cl} \\
-0.1 \%-3.5 \%)\end{array}$ \\
\hline & & $n=5$ & $\mathrm{n}=1$ & $\mathrm{n}=4$ & & & & & & \\
\hline & $\begin{array}{l}\text { Obtain medication } \\
\text { information from MD } \\
\text { offices }\end{array}$ & $\begin{array}{c}12.3 \\
(95 \% \mathrm{Cl} \\
4.3-20.3)\end{array}$ & 9 & $\begin{array}{c}13.3 \\
(95 \% \mathrm{Cl} \\
2.5-24.2)\end{array}$ & $\mathrm{N} / \mathrm{A}^{\prime}$ & $\begin{array}{c}1.6 \\
(95 \% \mathrm{Cl} \\
-0.1-3.4)\end{array}$ & $\begin{array}{c}0.8 \\
(95 \% \mathrm{Cl} \\
-0.7-2.2)\end{array}$ & $\begin{array}{c}2.2 \\
(95 \% \mathrm{Cl} \\
-0.6-5.0)\end{array}$ & .44 & $\begin{array}{c}1.1 \% \\
(95 \% \mathrm{Cl} \\
0.0-2.2)\end{array}$ \\
\hline & & $n=4$ & $n=1$ & $\mathrm{n}=3$ & & & & & & \\
\hline & $\begin{array}{l}\text { Obtain medication } \\
\text { information from dialysis } \\
\text { centers }\end{array}$ & $\begin{array}{c}7.8 \\
(95 \% \mathrm{Cl} \\
3.9-11.6)\end{array}$ & 11 & $\begin{array}{c}6.7 \\
(95 \% \mathrm{Cl} \\
2.1-11.2)\end{array}$ & $N / A^{\prime}$ & $\begin{array}{c}1.1 \\
(95 \% \mathrm{Cl} \\
0.0-2.2)\end{array}$ & $\begin{array}{c}0.9 \\
(95 \% \mathrm{Cl} \\
-0.9-2.7)\end{array}$ & $\begin{array}{c}1.1 \\
(95 \% \mathrm{Cl} \\
-0.2-2.5)\end{array}$ & .86 & $\begin{array}{c}1.3 \% \\
(95 \% \mathrm{Cl} \\
0.1-2.6)\end{array}$ \\
\hline & & $\mathrm{n}=4$ & $\mathrm{n}=1$ & $n=3$ & & & & & & \\
\hline & $\begin{array}{l}\text { Obtain medication } \\
\text { information from SNFs }\end{array}$ & $\begin{array}{c}11.1 \\
(95 \% \mathrm{Cl} \\
8.7-13.5)\end{array}$ & $\begin{array}{c}11.7 \\
(95 \% \mathrm{Cl} \\
9.9-13.4)\end{array}$ & $\begin{array}{c}10.8 \\
(95 \% \mathrm{Cl} \\
7.2-14.4)\end{array}$ & .77 & $\begin{array}{c}3.3 \\
(95 \% \mathrm{Cl} \\
1.3-5.3)\end{array}$ & $\begin{array}{c}2.9 \\
(95 \% \mathrm{Cl} \\
-0.1-5.9)\end{array}$ & $\begin{array}{c}3.6 \\
(95 \% \mathrm{Cl} \\
0.9-6.3)\end{array}$ & .74 & $\begin{array}{c}6.1 \% \\
(95 \% \mathrm{Cl} \\
2.1-10.1)\end{array}$ \\
\hline & & $\mathrm{n}=9$ & $\mathrm{n}=3$ & $\mathrm{n}=6$ & & & & & & \\
\hline $\begin{array}{l}\text { Utilizing } \\
\text { Electronic } \\
\text { Health Record }\end{array}$ & $\begin{array}{l}\text { Review the patient's } \\
\text { EHR prior to seeing the } \\
\text { patient' } \\
\text { Update AMH in EHR and } \\
\text { document pharmacist } \\
\text { verification of the AMH } \\
\text { Write pharmacist AMH } \\
\text { note }^{\text {h }} \\
\text { Complete order for phar- } \\
\text { macist to obtain AMH }\end{array}$ & $\begin{array}{c}30.1 \\
(95 \% \mathrm{Cl} \\
24.5-35.6) \\
n=30\end{array}$ & $\begin{array}{c}32.0 \\
(95 \% \mathrm{Cl} \\
25.4-38.6) \\
\mathrm{n}=12\end{array}$ & $\begin{array}{c}28.8 \\
(95 \% \mathrm{Cl} \\
20.5-37.2) \\
\mathrm{n}=18\end{array}$ & .60 & $\begin{array}{c}30.1 \\
(95 \% \mathrm{Cl} \\
24.5-35.6)\end{array}$ & $\begin{array}{c}32.0 \\
(95 \% \mathrm{Cl} \\
25.4-38.6)\end{array}$ & $\begin{array}{c}28.8 \\
(95 \% \mathrm{Cl} \\
20.5-37.2)\end{array}$ & .60 & $\begin{array}{c}42.8 \% \\
(95 \% \mathrm{Cl} \\
37.4-48.2)\end{array}$ \\
\hline $\begin{array}{l}\text { Pharmacist } \\
\text { Supervision of } \\
\text { Technicians }\end{array}$ & $\begin{array}{l}\text { Provide workflow } \\
\text { guidance, if needed } \\
\text { Verify technician } \\
\text { completed AMHk } \\
\text { Verify technician AMH } \\
\text { with patient and/or } \\
\text { secondary resources, if } \\
\text { needed } \\
\text { Provide feedback for } \\
\text { technician AMH errors, } \\
\text { if needed }\end{array}$ & $\begin{array}{c}26.0 \\
(95 \% \mathrm{Cl} \\
14.9-37.1) \\
\mathrm{n}=18\end{array}$ & $\mathrm{n}=0$ & $\begin{array}{c}26.0 \\
(95 \% \mathrm{Cl} \\
14.9-37.1) \\
\mathrm{n}=18\end{array}$ & $\mathrm{~N} / \mathrm{A}^{\prime}$ & $\begin{array}{c}26.0 \\
(95 \% \mathrm{Cl} \\
14.9-37.1) \\
\mathrm{n}=18\end{array}$ & $\mathrm{n}=0$ & $\begin{array}{c}26.0 \\
(95 \% \mathrm{Cl} \\
14.9-37.1) \\
n=18\end{array}$ & $N / A^{\prime}$ & $\begin{array}{c}17.3 \% \\
(95 \% \mathrm{Cl} \\
10.8-23.8)\end{array}$ \\
\hline Miscellaneous & Request interpreter & $\begin{array}{l}8.0 \\
n=1\end{array}$ & $\begin{array}{l}8.0 \\
n=1\end{array}$ & $n=0$ & $\mathrm{~N} / \mathrm{A}^{\prime}$ & $\begin{array}{c}0.3 \\
(95 \% \mathrm{Cl} \\
-0.3-0.8)\end{array}$ & $\begin{array}{c}0.7 \\
(95 \% \mathrm{Cl} \\
-0.6-2.0)\end{array}$ & $n=0$ & $N / A^{\prime}$ & $\begin{array}{c}0.3 \% \\
(95 \% \mathrm{Cl} \\
-0.3-0.9)\end{array}$ \\
\hline
\end{tabular}

Total time to obtain an AMH includes tasks below. Note: Not all tasks are required for each AMH.

'Comparison of mean time to complete tasks for pharmacists vs. PSPTs using two sample t tests.

'May include discussing the following: Introducing self to patient and assessing mental status; identifying the patient's primary caregiver for medications, if not the patient; reviewing the patient's medication list and/or pill bottles, if available; reviewing prescription medications, OTC medications, and non-oral medications; assessing patient medication literacy and adherence; providing medication education; determining last dose of medications; and obtaining pharmacy/secondary resource information.

TTime to obtain pharmacy fill data.

eMay include the following: Reviewing SNF MAR sent with patient; calling SNFs for medication list or to fax SNF MAR, if not sent with the patient; and calling SNF for clarification of SNF MAR.

'May include reviewing the following: Current unvalidated AMH; subjective and objective patient information for current admission; recent hospitalizations; and recent outpatient records.

9May include updating the following: Deleting, modifying, and adding medications based on validated AMH; selecting EHR medication entries, while considering inpatient formulary and ensuring patients are discharged on home medications vs. formulary substitutions; and providing time of last dose of medications for scheduling of first inpatient dose, if ordered.

"May include documenting the following: Resources utilized to obtain the AMH; outpatient, hospital discharge, or long-term care facility medication errors; patient self-adjustments or self-discontinuing of medications; recent significant MD changes; patient medication adherence or literacy issues; and patient medication concerns.

Pharmacist time to supervise PSPTs.

May include providing guidance for the following: Information that needs to be clarified with the patient; next steps in reconciling sources of information; how to update the AMH in the EHR.

Based on sources of information obtained by the PSPT and PSPT presentation of AMH.

Unable to calculate $P$ value due to inadequate $n$ in each arm.

NOTE: Abbreviations: AMH, admission medication history; Cl, confidence interval; EHR, electronic health record; MAR, medication administration record; MD, medical doctor; OTC, over-the-counter; PSPTs, pharmacist-supervised pharmacy technicians; SNF, skilled nursing facility. 


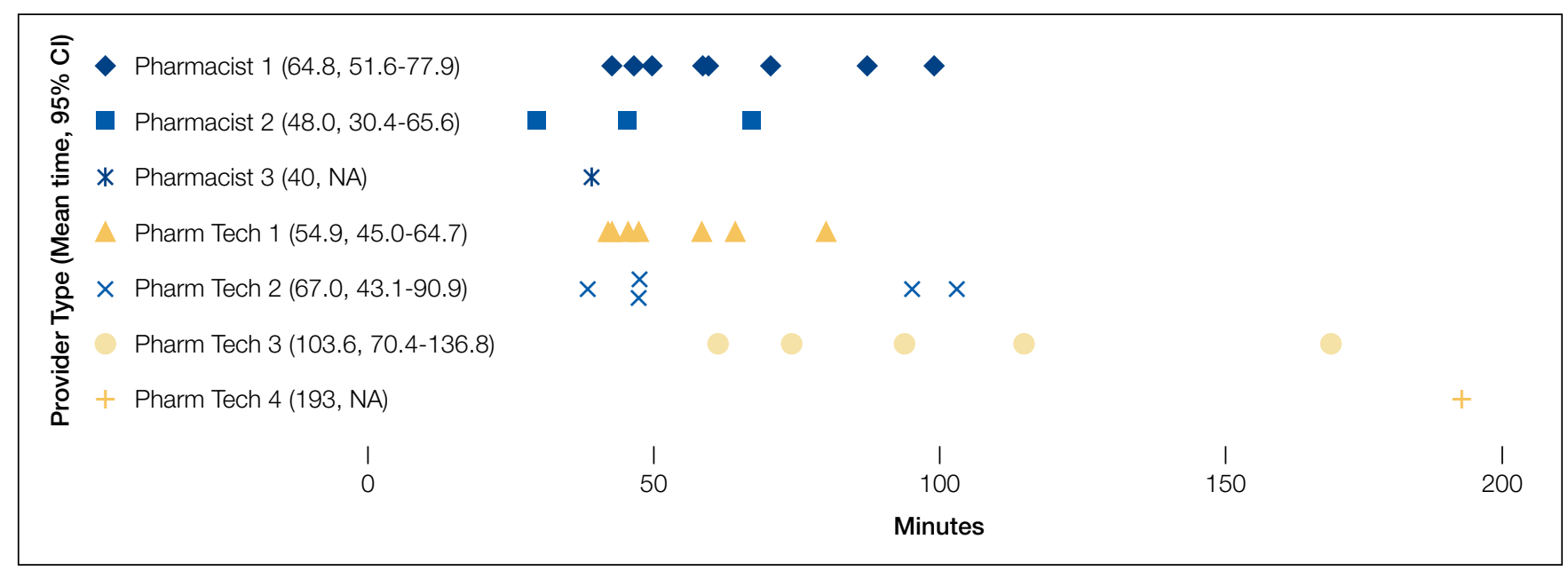

FIG. Time necessary for pharmacists and pharmacist-supervised pharmacy technicians to obtain an admission medication history.

NOTE: Abbreviation: $\mathrm{Cl}$, confidence interval.

We calculated Pearson product-moment correlation estimates between AMH time and these continuous variables: patient age; total number of EHR medications; number of chronic EHR medications; years of provider AMH experience; and years of provider general pharmacy experience. Using two sample $t$ tests, we also checked for associations between $\mathrm{AMH}$ time and the following categorical variables: sex; presence of a patient-provided medication list; caregiver availability; and altered mental status, as determined by review of the ED physician's note. Caregiver availability was defined as the availability of a family member, caregiver, or medication administration record (MAR) for patients residing at a skilled nursing facility (SNF). The rationale for combining these variables is that SNF nurses are the primary caregivers responsible for administering medications, and the MAR is reflective of their actions.

After reviewing our initial data, we decided to increase our sample size from 20 to 30 complete AMHs. Because the trial had concluded, we selected 10 additional patients who met trial criteria and who would already have an AMH obtained by pharmacy staff for operational reasons. The only difference with the second set of patients $(n=10)$ is that we did not randomize patients into each arm, but chose to focus on AMHs obtained by PSPTs, as there is a greater need in the literature to study PSPTs. After finalizing data collection, the aforementioned analyses were conducted on the complete data set.

Lastly, we estimated the mean labor cost for pharmacists and PSPTs to obtain an AMH by using 2015 US BLS hourly wage data for pharmacists $(\$ 57.34)$ and pharmacy technicians $(\$ 15.23) .^{7}$ The cost for a pharmacist-obtained AMH was calculated by multiplying the measured mean time a pharmacist needed to obtain an AMH by $\$ 57.34$ per hour. The cost for a PSPT-obtained AMH was the sum of the PSPT's measured mean time to obtain an AMH multiplied by $\$ 15.23$ per hour and the measured mean pharmacist supervisory time multiplied by $\$ 57.34$ per hour.

\section{RESULTS}

Of the 37 observed AMHs, 30 had complete data. Seven AMHs were excluded because not all task times were recorded, due to the schedule restraints of the research nurse. Pharmacists and PSPTs obtained 12 and 18 AMHs, respectively. Mean patient ages were 83.3 (95\% confidence interval [CI], 77.3-89.2) and 79.8 (95\% CI, 71.5-88.0), for pharmacists and PSPTs, respectively $(P=0.55)$. Patient's EHRs contained a mean of 14.3 (95\% CI, 11.2-17.5) and 16.3 (95\% CI, 13.2-19.5) medications, prior to pharmacists and PSPTs obtaining an $\mathrm{AMH}$, respectively $(P=0.41)$.

The mean time pharmacists and PSPTs needed to obtain an $\mathrm{AMH}$ was 58.5 (95\% CI, 46.9-70.1) and 79.4 (95\% CI, 59.1-99.8) minutes, respectively $(P=0.14)$. Summary time data per provider is reported in the Figure. The mean time for pharmacist supervision of technicians was 26 (95\% CI, 14.9-37.1) minutes. Mean times of tasks and comparisons of these means times between providers are reported in the Table. The percent mean time for each task per patient for providers combined is also reported in the Table, in which utilizing the EHR was associated with the greatest percentage of time spent at $42.8 \%$ (95\% CI, 37.4-48.2).

In the 18 cases for which a caregiver (or SNF medication list) was available, providers needed only 58.1 (95\% CI, 44.1-72.1) minutes to obtain an $\mathrm{AMH}$, as compared with 90.5 (95\% CI, 67.9-113.1) minutes for the 12 cases lacking these resources $(P=0.02)$. We also found that among PSPTs, years of AMH experience were positively correlated with AMH time (coefficient of correlation 0.49, $P=0.04$ ). No other studied variables were correlated with or associated with differential AMH times.

We estimated mean labor costs for pharmacists and PSPTs to obtain AMHs as $\$ 55.91$ (95\% CI, 44.9-67.0) and $\$ 45.00$ (95\% CI, 29.7-60.4) per patient, respectively $(P=0.32)$. In the latter case, $\$ 24.85$ (95\% CI, 14.3-35.4) of the $\$ 45.00$ would be needed for pharmacist supervisory time. The labor cost for a PSPT-obtained AMH (\$45.00) was the sum of the PSPT's 
mean time (79.4 minutes) multiplied by technician wage data (\$15.23/hour) and supervising pharmacist's mean time (26.0 minutes) multiplied by pharmacist wage data ( $\$ 57.34 /$ hour).

\section{DISCUSSION}

Although limited by sample size, we observed no difference in time or costs of obtaining AMHs between pharmacists and PSPTs. Several prior studies reported that pharmacists and technicians needed less time to obtain AMHs (20-40 minutes), as compared with our findings. ${ }^{12-14}$ However, most prior studies used younger, healthier patients. Additionally, they used clinician self-reporting instead of third-person observer time and motion methodology. Indeed, the pharmacist times we observed in this study were consistent with prior findings ${ }^{6}$ that used accepted third-person observer time and motion methodology. ${ }^{10}$

We observed more variation in time to obtain AMHs among PSPTs than among pharmacists. While variation may be at least in part to the greater number of technicians studied, variation also points to the need for training and oversight of PSPTs. Selection of PSPTs with prior experience interacting with patients and functioning with higher levels of autonomy, standardized training of PSPTs, and consistent dedication of trained PSPTs to AMH functions to maintain their skills, may help to minimize such variation.

Limitations include the use of a single center and a small sample size. As such, the study may be underpowered to demonstrate statistically significant differences between providers. Furthermore, 7 AMHs (19\%) had to be excluded because complete task times were missing. This was exclusively because the workday of the research nurse ended before the AMH had been completed. Another limitation was that the tasks observed could have been dissected further to identify even more specific factors that could be targeted to decrease AMH times. We recommend that future studies be larger, investigate in more depth various factors associated with time needed to obtain AMHs, consider which patients would most likely benefit from PSPTs, and use a measure of value (eg, number of history errors prevented/dollar spent).

In summary, we found that PSPTs can obtain AMHs for similar cost to pharmacists. It will be especially important to know whether PSPTs maintain the accuracy documented in prior studies. ${ }^{8-9}$ If that continues to be the case, we expect our findings to allow many hospitals to implement programs using PSPTs to obtain accurate AMHs.

\section{Acknowledgments}

The authors thank Katherine M. Abdel-Razek for her role in data collection.

Disclosure: This research was supported by NIH/National Center for Advancing Translational Science UCLA CTSI Grant Number KL2TR000122 and National Institute on Aging Grant Number K23 AG049181-01 (Pevnick). The content is solely the responsibility of the authors and does not necessarily represent the official views of the NIH. The investigators retained full independence in the conduct of this research.

\section{References}

1. Mergenhagen KA, Blum SS, Kugler A, et al. Pharmacist-versus physician-initiated admission medication reconciliation: impact on adverse drug events. Am J Geriatr Pharmacother. 2012;10(4):242-250.

2. Mills PR, McGuffie AC. Formal medication reconciliation within the emergency department reduces the medication error rates for emergency admissions. Emerg Med J. 2010;27(12):911-915.

3. Boockvar KS, LaCorte HC, Giambanco V, Fridman B, Siu A. Medication reconciliation for reducing drug-discrepancy adverse events. Am J Geriatr Pharmacother. 2006;4(3):236-243.

4. Mueller SK, Sponsler KC, Kripalani S, Schnipper JL. Hospital-based medication reconciliation practices: a systematic review. Arch Intern Med. 2012;172(14):10571069.

5. Lee KP, Hartridge C, Corbett K, Vittinghoff E, Auerbach AD. "Whose job is it, really?" Physicians', nurses', and pharmacists' perspectives on completing inpatient medication reconciliation. J Hosp Med. 2015;10(3):184-186.

6. Meguerditchian AN, Krotneva S, Reidel K, Huang A, Tamblyn R. Medication reconciliation at admission and discharge: a time and motion study. BMC Health Serv Res. 2013;13:485.

7. Bureau of Labor Statistics, US Department of Labor, Occupational Employment Statistics, May 2015. Pharmacists and Pharmacy Technicians. http://www.bls.gov/ oes/. Accessed July 15, 2016.

8. Johnston R, Saulnier L, Gould O. Best possible medication history in the emergency department: comparing pharmacy technicians and pharmacists. Can J Hosp Pharm. 2010;63(5):359-365.

9. Pevnick JM, Nguyen CB, Jackevicius CA, et al. Minimizing medication histories errors for patients admitted to the hospital through the emergency department: a three-arm pragmatic randomized controlled trial of adding admission medication history interviews by pharmacists or pharmacist-supervised pharmacy technicians to usual care. J Patient Cent Res Rev. 2015;2:93.

10. Zheng K, Guo MH, Hanauer DA. Using the time and motion method to study clinical work processes and workflow: methodological inconsistencies and a call for standardized research. J Am Med Inform Assoc. 2011;18(5):704-710.

11. Schrimpf D, Plotnicki L, Pilz LR. Web-based open source application for the randomization process in clinical trials: RANDI2. Int J Clin Pharmacol Ther. 2010;48(7):465-467.

12. American Society of Health-System Pharmacists and the American Pharmacists Association. ASHP-APhA medication management in care transitions best practices. http://media.pharmacist.com/practice/ASHP_APhA_MedicationManagementinCareTransitionsBestPracticesReport2_2013.pdf. Accessed January 15, 2016.

13. Kent AJ, Harrington L, Skinner J. Medication reconciliation by a pharmacist in the emergency department: a pilot project. Can J Hosp Pharm. 2009;62(3): 238-242.

14. Sen S, Siemianowski L, Murphy M, McAllister SC. Implementation of a pharmacy technician-centered medication reconciliation program at an urban teaching medical center. Am J Health Syst Pharm. 2014;71(1):51-56. 